\title{
La localidad de Valentín Alsina y el proyecto de creación del partido de Hipólito Vieytes: Autonomía municipal y oposición local hacia 1920
}

The town of Valentín Alsina and the municipality creation project of Hipólito Vieytes: Municipal autonomy and local opposition around 1920.

Denise Rocio Ganza

CONICET - Instituto de Investigaciones Gino Germani (Universidad de Buenos Aires), Argentina

deniseganza@yahoo.com.ar

\section{RESUMEN:}

Este trabajo analiza el fallido proceso de creación del partido de Hipólito Vieytes en los albores de 1920, y las formas de oposición que provocó en la localidad de Valentín Alsina. La indagación opta por lo local como nivel principal de análisis y se vale de dos tipos de fuentes: los diarios de sesiones de la Legislatura bonaerense y el diario La Libertad de Avellaneda. El estudio aporta al conocimiento de los posicionamientos de los distintos partidos políticos y su competencia electoral, los intereses divergentes de distintos sectores sociales, las modalidades de constitución de nuevos distritos, y la relación de Valentín Alsina con los municipios que la cobijaron.

Palabras Clave: Valentín Alsina, Avellaneda, Lanús, Autonomía municipal, Oposición local.

\section{ABstract:}

This work analyzes the failed process of creation of the municipality of Hipólito Vieytes in the dawn of 1920, and the forms of opposition that it provoked in the town of Valentín Alsina. The investigation opts for the local perspective as the main level of analysis and use two types of sources: the parliamentary reports of the Buenos Aires Legislature and La Libertad newspaper of Avellaneda. The study contributes to the knowledge of the political party stances and they electoral competition, the divergent interests of the social sectors, the forms of the constitution of the new districts, and the relationship of Valentin Alsina with the municipalities that it integrated.

KeYWORDS: Valentín Alsina, Avellaneda, Lanús, Municipal autonomy, Local opposition.

\section{INTRODUCCIÓN}

Este trabajo se propone realizar una contribución al estudio del Gran Buenos Aires, a través del análisis del fallido proceso de creación del partido de Hipólito Vieytes que, en los albores de 1920, pretendió infructuosamente dividir el ejido de Avellaneda, aunque terminaría por constituirse en un importante antecedente de la autonomía de Lanús. Asimismo, nos ocuparemos de estudiar las formas de oposición que este plan provocó en la localidad de Valentín Alsina. Esta elección temática obedece a diversos motivos.

En primer lugar, es preciso tomar en consideración que, en comparación con el volumen de estudios centrados en el análisis de la Capital Federal, nuestros conocimientos acerca de la evolución histórica de la provincia de Buenos Aires son francamente menores. Al respecto, Juan Manuel Palacio (2012) señaló que la íntima vinculación entre la historia de la provincia de Buenos Aires y la historia nacional ha impedido tanto el análisis diferenciado y contundente de, como la existencia de intentos de reconstruir su pasado de forma completa. No obstante, existieron contribuciones relevantes, las cuales a grandes rasgos se sucedieron entre la obra pionera Historia de la Provincia de Buenos Aires y formación de sus pueblos, dirigida por Ricardo Levene (1941), y la aparición reciente de una Historia de la Provincia de Buenos Aires en seis tomos (Palacio, 2013; Barreneche, 2014). ${ }^{1}$

Recepción: 20 de marzo de 2018 | Aprobación: 24 de septiembre de 2018 | Publicación: 28 de mayo de 2019 
Por otra parte, el interés por la evolución histórica del área del Gran Buenos Aires ha redundado en un número aún menor de investigaciones académicas. Hasta la fecha, el último tomo de la ya mencionada colección Historia de la Provincia de Buenos Aires (Kessler, 2015) es el único estudio que aborda la cuestión desde una perspectiva de conjunto. Esta situación contrasta con el interés manifestado por otras disciplinas, como la Sociología y la Antropología, que han mostrado una mayor preocupación por el análisis de las zonas urbanas del espacio bonaerense para periodos más recientes, bajo la forma del Área Metropolitana de Buenos Aires (AMBA), que permite un análisis integrado de la ciudad porteña y sus alrededores. ${ }^{2}$

En el orden municipal, los abordajes también son escasos, con las destacables excepciones de los tempranos esfuerzos emprendidos por el archivo histórico provincial, en el marco de cuya colección "Contribución a la historia de los pueblos de la Provincia de Buenos Aires" se produjeron, por ejemplo, los trabajos de Antonio Torassa (1940) sobre Avellaneda y Alberto de Paula, Ramón Gutiérrez y Graciela Viñuales (1974) acerca de los antecedentes históricos del actual partido de Lanús. Los otros estudios hallados acerca de la historia de estos partidos constituyen un conjunto heterogéneo, cuya principal coincidencia radica en su intención de divulgación de la historia local, al mismo tiempo que en su casi exclusiva atención sobre la cronología de los hechos y la vida de ciertas personalidades destacadas de la comunidad, perdiendo de vista procesos más generales. ${ }^{3}$ Por su parte, los aportes específicos acerca de la localidad de nuestro interés se encuentran prácticamente limitados a la destacable labor de la Junta de Estudios Históricos de Valentín Alsina, que desde 1994 organiza periódicamente el "Congreso Histórico-Geográfico del Pago del Riachuelo".

En otro orden de ideas, este estudio opta por lo local como principal nivel de análisis. Esta preferencia obedece a algunas de las ventajas que el quehacer historiográfico del campo de la historia regional y local ha demostrado. Por un lado, la posibilidad de introducir matices respecto de las perspectivas más generales y cuestionar las verdades recurrentes a través del análisis de casos diversos, cuyas particularidades y relaciones con la historia general son puestas en evidencia (Bandieri, 2001, p. 103; Bandieri, 2007, p. 47; Carbonari, 2009, p. 31; S. Fernández, 2008; Terradas I Saborit, 2001, p. 179). Pero, además, la oportunidad de rescatar la experiencia de la cotidianeidad y observar la acción humana concreta (Carbonari, 2009, p. 29; Jensen, 2010, p. 1430; Medina Rubio, s.f., p. 90; Pons y Serna, 2007, p. 27). ${ }^{4}$

En este caso, nos centraremos en el análisis de la localidad de Valentín Alsina, tomando en consideración que la misma reúne algunas características particulares que la convierten en un espacio privilegiado para el análisis de las profundas transformaciones acontecidas en la provincia de Buenos Aires a fines del siglo XIX y principios del XX. ${ }^{5}$ Nos referimos especialmente a las zonas aledañas a la Capital Federal, donde los procesos de urbanización e industrialización, hasta entonces privativos de la ciudad porteña, comenzaron a ganar relevancia, y la periferia urbana se integró a la ciudad a través del ferrocarril y el tranvía (Ferrer, 2010; Míguez, 2013; Rapoport, 2006). Además, la provincia de Buenos Aires se vio afectada por un marcado incremento de la población de origen extranjero, principalmente proveniente de ultramar, cuya radicación provocó un amplio impacto demográfico, económico, social y cultural en el espacio bonaerense (De Cristóforis, 2016; Devoto, 2003; A. Fernández, 2013).

A todo lo anterior se sumaron, finalmente, las transformaciones provenientes del ámbito de la política, algunas de las cuales nos ocuparán en este artículo. A lo largo del presente trabajo, procuraremos dar cuenta del derrotero del proyecto de creación del partido de Hipólito Vieytes. Optaremos por enfocar este problema desde el espacio de Valentín Alsina, una de las localidades que hubiera integrado el nuevo partido, de haber llegado a buen término su conformación. Esta elección se relaciona fundamentalmente con dos cuestiones: la existencia de abundantes referencias a la oposición de determinados sectores de la localidad a la concreción del proyecto, y las particularidades del desarrollo de Valentín Alsina, las cuales, de alguna manera, la colocaban en un lugar de competencia respecto de Lanús en tanto futura localidad cabecera.

Para conocer el derrotero del proyecto legislativo presentado en 1918, nos valdremos de la información contenida en los diarios de sesiones de la Legislatura bonaerense. En cuanto a la observación de las manifestaciones de disconformidad expresadas en la localidad de nuestro interés, nos detendremos en el 
análisis de las noticias referentes a Valentín Alsina aparecidas en el diario La Libertad de Avellaneda durante los años 1919 y 1920.

Además, ambas cuestiones serán una vía para aproximarnos a problemas diversos: los posicionamientos de los partidos políticos y su competencia electoral en el territorio bonaerense, los intereses divergentes de distintos sectores sociales, las modalidades de constitución de nuevos distritos y, fundamentalmente, la relación de Valentín Alsina con los partidos que la cobijaron, aspecto de vital importancia para observar las particularidades del desarrollo de la localidad de nuestro interés y la configuración de una identidad propia.

\section{VALENTín Alsina: BREVE RESEÑa Histórica}

Valentín Alsina es una localidad de la provincia de Buenos Aires, emplazada en el área ribereña del Riachuelo, dentro de la jurisdicción del partido de Lanús. ${ }^{6}$ Se encuentra unida a la Ciudad Autónoma de Buenos Aires por el popularmente denominado Puente Alsina, a través del cual se comunica con el barrio porteño de Nueva Pompeya. No obstante, hasta la concreción de la autonomía de Lanús en 1944, Valentín Alsina integró el partido de Avellaneda, previamente denominado Barracas al Sud.

Sobre su evolución histórica, de Paula, Gutiérrez y Viñuales (1974) destacaron que Valentín Alsina tuvo un desarrollo independiente y similar al de la cabecera del partido de Barracas al Sud, lo cual distinguió a esta localidad de otras del mismo distrito, también surgidas al calor de los loteos de las décadas de 1870 y 1880 en el área del actual partido de Lanús. Señalaron que:

...su evolución urbana posterior presenta analogías con la de Barracas al Sud; ésta debe su desarrollo al Puente de Gálvez (Puente Pueyrredón) a la avenida Mitre y a los saladeros, aquélla lo debe al Puente Alsina (Puente Uriburu) a la avenida Remedios de Escalada y a los saladeros y posteriores fuentes de trabajo (p. 132).

\section{FIGURA 1}

Plano del pueblo Valentín Alsina (1875)

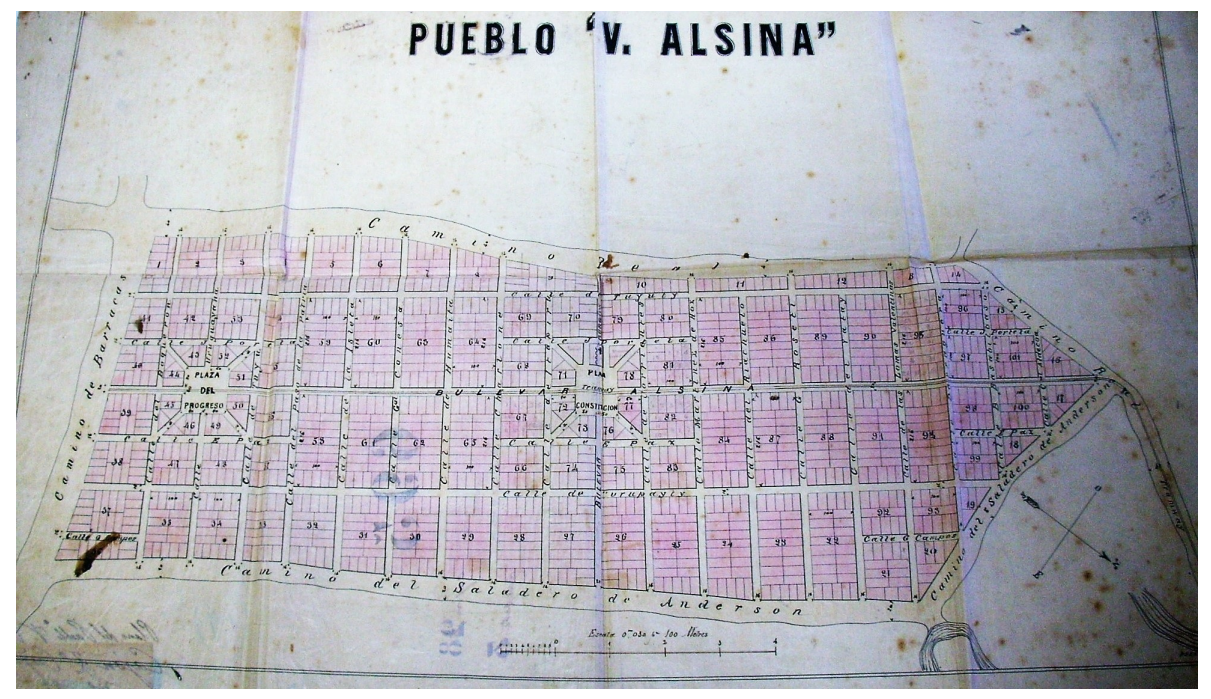

Archivo Histórico y Cartográfico de la División de Geodesia de la Provincia de Buenos Aires, Plano del pueblo Valentín Alsina, N. ${ }^{\circ} 69528$ 3, 1875.

El llamado Puente Alsina es el único que une el partido de Lanús con la Ciudad Autónoma de Buenos Aires. ${ }^{7}$ Un puente de madera fue erigido en 1859 y bautizado "Valentín Alsina" en honor al reciente gobernador de la provincia de Buenos Aires, quien se encontraba presente en el evento de inauguración (Álvarez, 1993; Ochoa, 1938, pp. 7-10). Haciendo extensivo el nombre del puente, el "Pueblo Alsina" fue creado oficialmente en el año 1875 a partir de un área de 101 manzanas, como parte de una secuencia de loteos que se efectuó durante esa década en territorios de la provincia (de Paula et al., 1974, pp. 123-125, 
pp. 138-149). El propietario de estos terrenos era Daniel Solier, quien en 1874 solicitó la aprobación de las autoridades bonaerenses para subdividir su propiedad en lotes, al tiempo que sugería la posibilidad de constituir una municipalidad independiente. ${ }^{8} \mathrm{El}$ decreto $\mathrm{N} .{ }^{\circ} 2864$ del gobierno provincial, expedido por el gobernador Carlos Casares el 6 de septiembre, autorizó la realización de la traza del pueblo (de Paula et al., 1974, pp. 132-133; Fernández Larrain, 1986, pp. 142-143). El mismo se ubicaría en la zona delimitada por el Camino Real al Puente Alsina (avenida Remedios de Escalada), el camino al saladero de Anderson (calles Coronel Luna - República Argentina) y el camino de Barracas (avenida Rivadavia).

FIGURA 2

Avisos de los remates de terrenos en Valentín Alsina (1875)

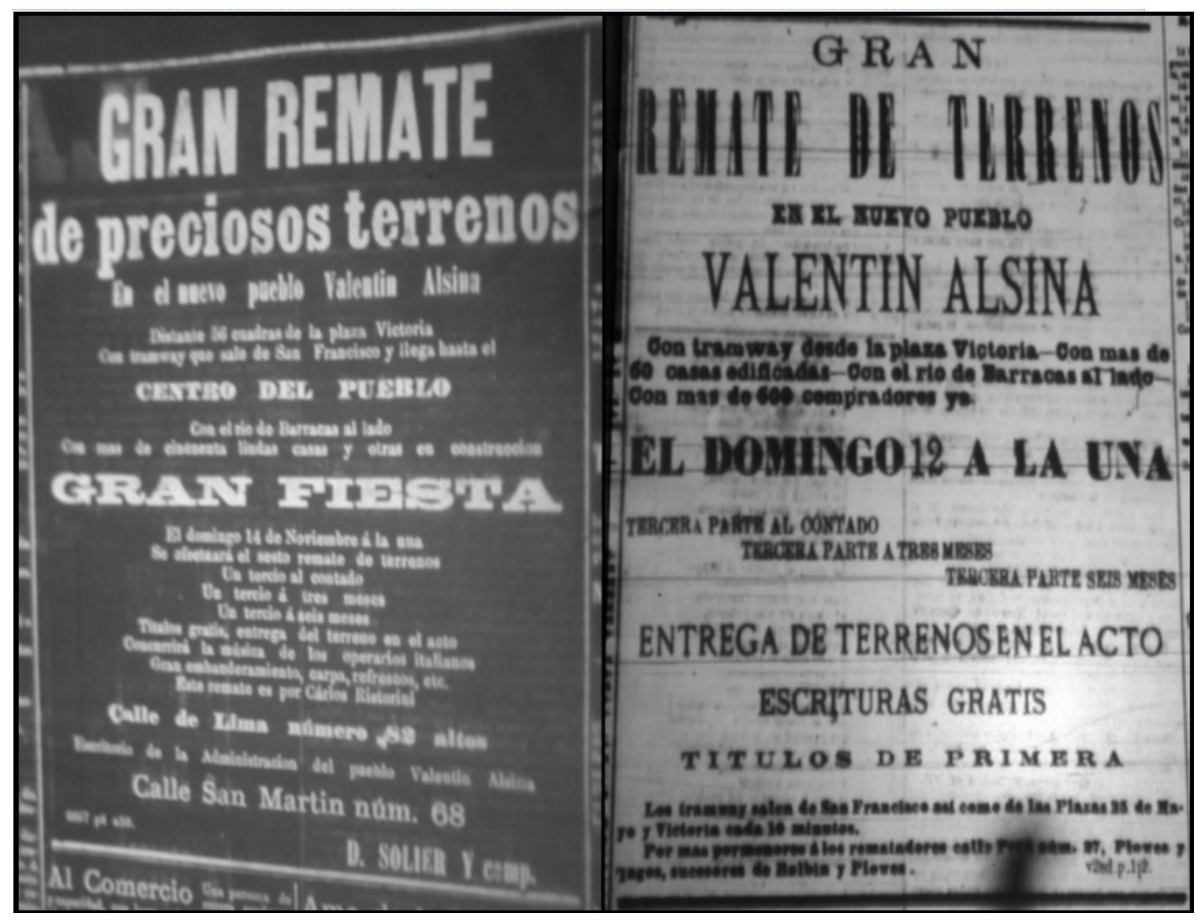

La Nación, 10 de noviembre de 1875, p. 2; La Prensa, 11 de diciembre de 1875, p. 2

Una serie de más de media docena de remates se llevó a cabo en Valentín Alsina entre octubre y diciembre de 1875 (La Nación, 10 de noviembre de 1875, p. 2; La Nación, 11 de noviembre de 1875, p. 2; La Prensa, 22 de octubre de 1875, p. 2; La Prensa, 29 de octubre de 1875, p. 2; La Prensa, 30 de octubre de 1875, p. 2; La Prensa, 31 de octubre de 1875, p. 2; La Prensa, 5 de noviembre de 1875, p. 2; La Prensa, 28 de noviembre de 1875, p. 2; La Prensa, 2 de diciembre de 1875, p. 2; La Prensa, 16 de diciembre de 1875, p. 2; La Prensa, 24 de diciembre de 1875, p. 2; La Prensa, 28 de diciembre de 1875, p. 2). Los avisos en la prensa nacional recurrían a la promoción de las bondades del flamante pueblo, tales como su cercanía respecto del Riachuelo y del centro de la ciudad de Buenos Aires o las facilidades de pago ofrecidas, y se invitaba a las grandes fiestas que coincidirían con la ejecución de los remates.

Las ventajas de accesibilidad de Valentín Alsina, asunto de importancia central para el desarrollo de las comunidades suburbanas (Scobie, 1977), fue mejorando progresivamente, en la medida que se multiplicaron los servicios tranviarios y se inauguró el trayecto del Ferrocarril Midland (actual línea Metropolitana del Ferrocarril General Belgrano) desde Puente Alsina hasta Carhué, entre 1908 y 1909 (Fernández Larrain, s.f., p. 3; Ippoliti, 1983, pp. 61-64; Pesado Palmieri, 1987, pp. 25-52).

En lo que refiere a las fuentes de trabajo disponibles, aunque la zona se vio afectada por la interrupción de la actividad de los saladeros en 1871 (Cutolo, 1998, p. 93), más tarde abrirían sus puertas dos emprendimientos industriales de vital relevancia para la zona. Por un lado, la fábrica de ponchos, mantas y frazadas Campomar Hnos. Fundada en 1883 por iniciativa del español Juan Campomar (Álbum Argentino, 1910, p. 55), fue la 
primera de varias industrias textiles muy representativas del ramo que se radicaron en la zona de Valentín Alsina (Ceva, 2010, pp. 55-56, p. 89).

El otro hito en el desarrollo industrial de la localidad fue la apertura del Frigorífico Argentino en el año 1905. ${ }^{9}$ Una compañía liderada por importantes propietarios rurales y presidida por el encumbrado industrial Antonio Devoto lo emplazó en los terrenos donde anteriormente funcionara el saladero de Anderson (Álbum Argentino, 1910, p. 171; Barbero, 2009). Algún tiempo después, la propiedad del frigorífico mudaría de manos y pasaría a ser popularmente conocido como Frigorífico Wilson. ${ }^{10}$

Finalmente, cabe destacar que existen serias dificultades para conocer la evolución poblacional de Valentín Alsina, en la medida que tanto las estadísticas nacionales como las provinciales suelen carecer de datos acerca de los parámetros demográficos para la escala estrictamente local. Algunas referencias indirectas indican que hacia fines del siglo XIX esta área era la única que, a diferencia del resto del territorio del actual partido de Lanús, no era eminentemente rural (Scaltritti, s.f., p. 2). En 1908, Valentín Alsina habría contado con unos cinco mil habitantes y una edificación modesta, de alrededor de un centenar de viviendas precarias (de Paula et al., 1974, p. 133). No obstante, solamente dos años después, la localidad era señalada como el tercer centro poblado del partido de Avellaneda por su desarrollo e importancia (Álbum Argentino, 1910, p. 122). Según los datos calculados por la Dirección General de Estadística de la Provincia de Buenos Aires (1926, p. 51), para el año 1924 la población habría mantenido una cifra similar desde 1908, alcanzando los 5.313 habitantes. Sin embargo, la cantidad resulta más abultada y se acerca a las siete mil personas si sumamos los datos correspondientes a Puente Alsina (290) y Parada Diamante (1.025), núcleos linderos generalmente asociados a la localidad de nuestro interés. Inclusive veremos luego que, en el marco de los debates por la autonomía del partido de Vieytes, le era atribuida una población más numerosa.

\section{El proyecto de Creación Del PARTido de Hipólito Vieytes: SU Derrotero LEGISLATIVO (1918-1920)}

\section{La presentación del proyecto y el debate en la Cámara de Diputados}

El 18 de julio de 1918, durante la 15.a sesión ordinaria del 65. periodo legislativo, el diputado radical Antonio Crespo presentó ante la Cámara de Diputados provincial el proyecto de ley para la creación de un nuevo partido en el ejido de Avellaneda, cuyo nombre sería José Hipólito Vieytes. ${ }^{11}$ Tal proyecto se constituyó en un importante antecedente para la posterior creación del partido de Lanús en 1944 puesto que, si bien no anticipaba exactamente los actuales límites del municipio, tendría cabecera en el pueblo homónimo.

La discusión del proyecto por parte de los diputados se demoró hasta fines del mes de agosto del año siguiente, 1919. Según afirmaciones vertidas por el diputado socialista José P. Baliño, la demora estuvo vinculada a la actitud de los diputados conservadores, quienes reticentes a un resultado favorable a la creación del nuevo partido no contribuían con su presencia al logro del quórum necesario (DSCD, 6 de agosto de 1919, p. 1188). Sin embargo, los prolegómenos del tratamiento del tema muestran también el carácter polémico del proyecto entre los vecindarios afectados, tanto como la situación paradójica en la que se encontraron algunos miembros del poder legislativo provincial. El diputado radical Vicente Damonte, por ejemplo, suscribió el proyecto de creación del partido de Vieytes, pero al mismo tiempo apoyó, parcialmente y por pedido de los vecinos de la zona, un proyecto de ley presentado por el conservador Felipe Castro para la incorporación de las localidades de Talleres y Villa Barceló a Lomas de Zamora, excluyéndolas del proyectado partido de Vieytes (DSCD, 20 de agosto de 1919, p. 1242).

Finalmente, el 27 de agosto de 1919, la cámara se dispuso a llevar a cabo la discusión en general del proyecto (DSCD, 27 de agosto de 1919, pp. 1384-1407). La Comisión Primera de Legislación, conformada por Antonio Crespo, Jacinto Oddone (Partido Socialista), A. Poblet Videla (Unión Cívica Radical) y Tomás 
Jofré (Partido Conservador), lo había analizado y recomendó la aprobación, con la disidencia del último diputado mencionado.

El debate suscitado a lo largo de la sesión legislativa evidenció claramente cuáles eran las posturas de los tres partidos que protagonizaban la escena política bonaerense tras la apertura democrática propiciada por la sanción de la Ley Sáenz Peña y se encontraban representados en la cámara. ${ }^{12}$ Mientras que los socialistas eran los más entusiastas defensores del proyecto, los conservadores se ubicaban en el extremo opuesto, mostrándose como acérrimos defensores de la integridad de Avellaneda, en cuya vida pública era central el caudillo conservador Alberto Barceló. ${ }^{13}$ Se ha señalado, inclusive, que fue su poder el que logró mantener indivisible la ciudad durante varias décadas (Folino, 1983, p. 63). Por su parte, los diputados radicales no defendían una postura unívoca y, en algunos casos, parecían proclives a atender las demandas vecinales, tal como lo demuestran la actitud de Damonte frente a la problemática de Talleres y las posturas adquiridas en relación con Valentín Alsina, las cuales veremos luego. ${ }^{14}$

La postura socialista fue sostenida por el diputado y futuro intendente de Avellaneda, Jacinto Oddone. ${ }^{15}$ Su argumentación giró en torno a la legitimidad de los reclamos autonomistas, la solvencia económica del futuro partido y el cuestionamiento de la pertinencia de las solicitudes contrarias al proyecto. Indicó que se trataba de manifestaciones minoritarias que respondían a los intereses de "los grandes capitalistas de Valentín Alsina, de los dueños del frigorífico, de los dueños de la hilandería de Campomar, se trata de los terratenientes, de los dueños de grandes extensiones de tierra" (DSCD, 27 de agosto de 1919, pp. 1398-1399). Asimismo, Oddone presentó una comunicación de los obreros del frigorífico de Valentín Alsina, en la cual le solicitaban que haga saber a la cámara que habían sido presionados por sus patrones para firmar distintos petitorios en contra del proyecto discutido (DSCD, 27 de agosto de 1919, p. 1399).

La exposición de la perspectiva de los conservadores corrió por cuenta de los diputados Jofré y Juan G. Kaiser, los cuales destacaron las divergencias de opinión ocasionadas por el proyecto entre la población de las diversas localidades y, en consecuencia, propusieron la realización de una consulta popular (DSCD, 27 de agosto de 1919, p. 1392). Asimismo, sugirieron la posibilidad de pedir su opinión a las autoridades de la municipalidad de Avellaneda, ante lo cual les fue señalada la contradicción respecto a su voto favorable en la creación reciente del partido de Leandro N. Alem, ocasión en la que no se dio intervención a la municipalidad de Lincoln (DSCD, 27 de agosto de 1919, p. 1404). Sobre el final del debate, se ocuparon de discutir distintos aspectos de la postura socialista. Acerca de la potencialidad financiera del nuevo partido, se refirieron a Lanús como el "dormitorio" de la ciudad de Buenos Aires y sostuvieron que, con motivo de su carencia de industrias y comercio, se intentaba "incorporar a ese nuevo distrito, poblaciones como Valentín Alsina y Talleres, donde efectivamente existen esos grandes recursos industriales" (DSCD, 27 de agosto de 1919, p. 1405). Por último, señalaron que el Partido Socialista tenía interés en la sanción del proyecto, dado que su "menor número de adherentes hace siempre necesario un escenario más reducido” (DSCD, 27 de agosto de 1919, p. 1399).

Durante el debate, las contradicciones en el bloque radical quedaron ejemplificadas por las posiciones de Crespo, quien presentara oportunamente el proyecto en discusión, y de Damonte. El primero se constituyó en uno de los principales defensores del reclamo autonomista y, en consonancia con las argumentaciones de los socialistas, dedicó sus esfuerzos en la cámara a mostrar las potencialidades del futuro partido y señalar como minoritarios los reclamos llegados a la Legislatura bonaerense en relación con la creación de Vieytes. Por su parte, el diputado Damonte, que había suscripto el proyecto de creación del nuevo partido, hizo saber durante la discusión que lo votaría afirmativamente en general. Sin embargo, aclaró que durante el tratamiento en particular pediría que se tomara en cuenta la solicitud de los vecinos de Talleres de ser incorporados a Lomas de Zamora (DSCD, 27 de agosto de 1919, p. 1390).

La sesión del 27 de agosto de 1919 resultó en la votación afirmativa del proyecto de ley, cuyo tratamiento en particular se efectuó los días 24 de septiembre y 1. de octubre del mismo año ( $D S C D, 24$ de septiembre de 1919, pp. 1583-1609; DSCD, $1 .^{\circ}$ de octubre de 1919, pp. 1638-1662). A lo largo del debate, se reiteraron algunos de los argumentos esgrimidos con anterioridad y adquirió gran relevancia la discusión acerca de 
la determinación de los límites definitivos del nuevo partido. El diputado conservador Enrique Barceló, hermano del caudillo avellanedense, habló de una "intentona de desmembramiento de Avellaneda" (DSCD, 24 de septiembre de 1919, p. 1583), uno de los partidos más pequeños de la provincia, y negó la pertinencia del argumento del abandono edilicio y de servicios para el caso de Lanús. También se refirió a la intención de incluir "dentro del nuevo partido a progresistas localidades como Talleres, Valentín Alsina, Villa de los Industriales y otras, cuya única ventaja si se sancionara el proyecto sería la de contribuir al pago de los nuevos impuestos" (DSCD, 24 de septiembre de 1919, p. 1585). Su compañero de bancada, Edgardo Míguez, completó la exposición defendiendo la oposición al proyecto de los empresarios de Valentín Alsina, en respuesta a las acusaciones vertidas anteriormente por los representantes socialistas ( $D S C D, 24$ de septiembre de 1919, pp. 1583 y 1604).

Tanto el radical Crespo como el socialista Oddone intentaron refutar las ideas de los diputados conservadores recurriendo a algunos de los argumentos que ya habían expuesto en el tratamiento en general del proyecto. No obstante, es interesante destacar que tanto Barceló como Oddone justificaron sus posiciones en el conocimiento derivado de su condición de vecinos de Avellaneda. El último se explayó acerca de la responsabilidad de las autoridades avellanedenses por el abandono de Lanús y vinculó la oposición al proyecto de los conservadores y algunos radicales de Avellaneda -entre quienes se mencionó al senador Agustín Debenedetti- a la intención de mantener el poder en el distrito. A propósito de ello, sostuvo que "cuando tenían la sartén por el mango los conservadores en Avellaneda, ellos eran los que se oponían a la creación del partido de una manera tenaz (...) Hoy se oponen los que manejan las cosas actualmente en la localidad" (DSCD, 24 de septiembre de 1919, p. 1593). ${ }^{16}$

Vale la pena destacar que esta sesión fue rica en la exposición de pedidos diversos provenientes de las zonas afectadas por el proyecto, a favor y en contra de su sanción. En este contexto, el radical Damonte reiteró la solicitud de excluir a Talleres del nuevo partido, y el conservador Kaiser planteó la exclusión de Valentín Alsina. Ambas propuestas fueron descartadas.

Llegado este punto, es preciso recapitular para sintetizar algunas de las cuestiones principales que parecieron estar en juego a lo largo del debate en la Cámara de Diputados. En primer lugar, las acusaciones mutuas entre socialistas y conservadores pusieron en evidencia el trasfondo de disputa electoral que acompañó el tratamiento del proyecto. Mientras los primeros podrían haber procurado ganar terreno valiéndose de la competencia en espacios jurisdiccionales más pequeños, los segundos parecían querer evitar el cuestionamiento de una autoridad largamente consolidada en el territorio avellanedense, pero recientemente disputada por los radicales.

Las intervenciones de los diputados evidencian que otro tipo de enfrentamiento puede haberse superpuesto a aquel. Si bien no hemos podido constatarlo a través de otras fuentes, los socialistas presentaban a los obreros como acérrimos defensores de la autonomía, mientras que existía una clara negativa de los empresarios de Valentín Alsina al proyecto de creación de Vieytes. Esta última situación quedará confirmada por nuestro análisis de las manifestaciones de resistencia a la autonomía que se dieron en la zona.

Por último, no puede dejar de señalarse que la creación de un nuevo partido en el territorio bonaerense ya había sido llevada a cabo en varias oportunidades anteriormente, así como volvería a serlo hasta tiempos recientes. Marcela Indiana Fernández (s.f.) propuso una distinción entre las nuevas jurisdicciones creadas como resultado de un proceso paulatino y las derivadas de un cambio puntual. El primer caso supone una progresiva ocupación y valorización de la zona, como condición para el crecimiento de demandas locales, mientras que el segundo deriva de decisiones tomadas casi exclusivamente en el ámbito gubernamental provincial. ${ }^{17}$ La conformación de Lanús resultaría, entonces, un buen ejemplo del primer tipo de procesos autonomistas. La prolongada existencia de reclamos autonomistas ${ }^{18}$ y las ocasiones en las que, durante el debate, los diputados hicieron referencia a las manifestaciones locales -a favor y en contra de la creación del nuevo partido- ponen en evidencia el rol activo de los vecinos. Asimismo, en el caso que nos ocupa cobran relevancia otros aspectos mencionados por Fernández, como los reclamos ante la desatención de las 
autoridades comunales y el refuerzo de las identidades de las pequeñas localidades, lo cual se evidencia tanto en la acción de los vecinos de Lanús, en tanto futura cabecera de partido, como en el propio caso de Valentín Alsina.

Asimismo, podemos señalar que la disconformidad con la gestión municipal, la elevación de petitorios vecinales, la presentación sin éxito de proyectos legislativos, los intensos debates parlamentarios donde se cuestionó la viabilidad económica de los nuevos municipios y los petitorios a favor y en contra de la creación de los nuevos partidos fueron elementos comunes al logro de la autonomía municipal en un importante número de casos, como por ejemplo Alberti -1910-, Esteban Echeverría -1911-, Tres de Febrero -1959-, Escobar -1959- y Berazategui -1960- (Beliera y Beliera, 1997, pp. 180-188; Callegari, 1993, pp. 31-43; Campomar, 1994, pp. 6-19, pp. 223-243; Greco, 1988, p. 43; Vaccarezza y Vaccarezza, 1972, pp. 107-110).

\section{El tratamiento en la Cámara de Senadores: fracaso del proyecto}

La aprobación del proyecto de creación del partido de Hipólito Vieytes por parte de la cámara baja, con las modificaciones pertinentes, fue comunicada al senado bonaerense algunos días después de la finalización de la discusión. ${ }^{19}$ Sin embargo, el tratamiento en la Cámara de Senadores habría de esperar hasta el mes de octubre de 1920, nada menos que un año después. Pero el año transcurrido fue de intensa actividad. La dilatada interrupción de las discusiones en el ámbito legislativo no implicó una situación análoga entre los vecindarios involucrados, tal como lo demuestra la multiplicación de petitorios, memoriales y manifestaciones enviadas por asociaciones de diverso tipo, comités políticos y vecinos particulares a favor y en contra de la sanción del proyecto.

Los debates en el senado se extendieron a lo largo del mes de octubre de 1920 (DSCS, 5 de octubre de 1920, pp. 388-413; DSCS, 19 de octubre de 1920, pp. 437-440, 442-445; DSCS, 26 de octubre de 1920, pp. 452-477). En esta ocasión, los argumentos expuestos enfrentaron fundamentalmente a dos senadores provinciales radicales: Agustín Debenedetti, vecino y concejal de Avellaneda, y Miguel Calderón.

Debenedetti manifestó una férrea oposición a la creación del partido de Hipólito Vieytes, con especial énfasis en la resistencia que el proyecto había ocasionado entre los vecinos de Valentín Alsina, y cuestionó el resultado favorable a la autonomía arrojado por un plebiscito (DSCS, 5 de octubre de 1920, p. 395). Además, recuperó el argumento de que Avellaneda se contaba entre los partidos menos extensos de la provincia y que su división lo reduciría a la categoría de los pueblos veraniegos, como Vicente López o Lomas de Zamora. En este sentido afirmaba que, por el contrario, "la ciudad, señor presidente, de las grandes fábricas, del poderoso comercio, servida por diversas vías férreas sobre dos puertos de mar, el Riachuelo y el Dock Sur necesitaría expansión para su porvenir y no compresión, que significa debilitamiento" (DSCS, 5 de octubre de 1920, p. 399).

En oposición a Debenedetti, Calderón se mostró favorable a la autonomía y destacó la importancia del principio de descentralización en todo el sistema administrativo y judicial de la provincia. También hizo referencia a la existencia de condiciones demográficas y fiscales favorables, así como expectativas de mejoramiento de la vida de la población comprendida en el futuro partido (DSCS, 5 de octubre de 1920, p. 391). Finalmente, se refirió al apoyo que el proyecto habría recibido por parte de los hombres de negocios.

La última parte del debate estuvo signada por la propuesta del senador Debenedetti de someter el tema a la opinión de la Comisión de Asuntos Constitucionales (DSCS, 66. ${ }^{\circ}$ periodo, 26 de octubre de 1920, p. 454).

A pesar de que el senado votó negativamente esta propuesta, la cámara se constituyó en comisión para definir el tema. Luego, tras una pequeña discusión acerca de la pertinencia de consultar a las municipalidades ante la posibilidad de que su ejido se viera afectado por la creación de un nuevo partido, el debate se interrumpió mediante la invitación a un cuarto intermedio y la posterior pérdida del quórum necesario. 
Sabemos que el proyecto no obtuvo la sanción definitiva en el Senado y que otros fueron presentados en los años 1922 -ocasión en la que se logró la aprobación de la cámara alta pero no se trató en la Cámara de Diputados-, 1926, 1927 y 1928. Como es conocido, la autonomía de Lanús no se haría efectiva hasta después del golpe de estado de 1943, cuando Edelmiro J. Farrel, oriundo de la zona, promovió la conformación del municipio de "Cuatro de Junio", creado mediante el decreto provincial N. 5321 del 29 de septiembre de 1944 (de Paula et al., 1974, pp. 158-161; González, 1944, pp. 21-23; Municipio de Lanús, 2014, pp. 7-8).

\section{VALENTÍN Alsina FRENTE a LAS REIVINDICACIONES AUTONOMisTaS DE LANÚS}

Ante el tratamiento legislativo del proyecto para la creación del partido de Vieytes, distintos sectores de la población de Valentín Alsina y Avellaneda llevaron a cabo importantes manifestaciones de oposición frente a la posibilidad de integrar un nuevo distrito. En las próximas páginas, nos ocuparemos de dar cuenta de estas reacciones, por medio del análisis de más de trescientas noticias acerca de Valentín Alsina aparecidas en el diario La Libertad ${ }^{20}$ de Avellaneda, afín a las demandas antiautonomistas, a lo largo de los años 1919 y 1920.

En el marco del periodo elegido para esta indagación, la cuestión de la oposición a las demandas autonomistas se convirtió en el principal asunto vinculado a aquella localidad tratado en este órgano de prensa. Los últimos días de febrero de 1919, el artículo titulado "La autonomía de Lanús. Una nota del pueblo de Valentín Alsina” no solo mostraba la vigencia del tema por aquellos días, sino que recordaba acciones anteriores. La publicación destacaba especialmente la presentación de un petitorio ante la Cámara de Diputados de la Provincia de Buenos Aires por parte del "Comité pro-exclusión de Valentín Alsina del proyectado partido de "Hipólito Vieytes", ante la inminencia del tratamiento de la creación del nuevo distrito ("La autonomía de Lanús", 25 de febrero de 1919, p.1). A continuación, las notas tituladas "Contra el desmembramiento de Avellaneda" se convirtieron prácticamente en una sección permanente de La Libertad.

Tres interrogantes básicos se presentan frente al análisis de la conformación de sectores opositores a la creación del partido de Vieytes, fundamentalmente en Valentín Alsina: quiénes eran los que encabezaron las manifestaciones a tal fin, cuáles eran sus argumentos y qué acciones se llevaron a cabo para conseguir los objetivos perseguidos.

En lo que refiere a la primera cuestión, debemos atender a la creación de dos agrupaciones que representaron la postura antiautonomista y se pusieron al frente de las iniciativas para evitar la creación del nuevo partido. Se trató, por un lado, de un comité constituido en la propia localidad y, por el otro, de una comisión conformada por iniciativa del Centro Industrial y Comercial de Avellaneda. Sus nombres fueron "Comité pro-separación de Valentín Alsina de la autonomía de Lanús" y "Comisión popular pro Avellaneda indivisible", respectivamente. En ambos casos, se destacó la presencia de industriales, comerciantes y profesionales, aunque en el segundo caso hubo una mayor participación de instituciones de la comunidad, de diverso tipo.

El primer antecedente de la creación de un comité en Valentín Alsina estuvo en el ya mencionado "Comité pro exclusión de Valentín Alsina del proyectado partido de 'Hipólito Vieytes" "La autonomía de Lanús”, 25 de febrero de 1919, p.1). No obstante, rápidamente, una asamblea celebrada en la Sociedad Italiana de Socorros Mutuos y presidida provisoriamente por el industrial textil Ugolino Giardino, designó una Comisión Honoraria de la que formarían parte industriales, comerciantes y profesionales de la zona, entre ellos Miguel Campomar y el Frigorífico Wilson ("Valentín Alsina",5 de agosto de 1919, p. 5). Unos días después se encontraría plenamente constituido al "Comité pro-separación de Valentín Alsina de la autonomía de Lanús”, con la confirmación de Ugolino Giardino como presidente y la compañía de una serie de industriales relevantes: Campomar, Frigorífico Wilson, Rafael Oliver y Cía., Caimari, Homar y Cía., J. Y. Zavaleta y Risotto.

Al mes siguiente, en septiembre de 1919, el Centro Industrial y Comercial de Avellaneda encabezó la convocatoria a una asamblea que se celebró el día 14 en el Centro Gallego de la misma localidad. La invitación 
fue remitida a varias instituciones a través de una circular y la asamblea sesionó con las adhesiones y los delegados de más de treinta instituciones del partido (“Contra la creación”, 14 de septiembre de 1919, p. 1; “Contra la desmembración”, 16 de septiembre de 1919, p. 1; “Contra el desmembramiento", 5 de noviembre de 1919, p. 3). ${ }^{21}$ Allí se aprobó un manifiesto y se generaron las condiciones para la conformación de la "Comisión popular pro Avellaneda indivisible", que adquirió su forma definitiva el día 21 de septiembre. Los delegados votaron una mesa directiva integrada, entre otros, por la autoridad máxima del Centro Comercial e Industrial, José L. García (presidente) y el conocido industrial de la zona de Valentín Alsina, Miguel Campomar (tesorero).

Ambos agrupamientos, el de Valentín Alsina y el de Avellaneda, mantuvieron vínculos muy fluidos entre sí, al tiempo que se relacionaron con instancias oficiales, en virtud del derrotero que la cuestión de la posible autonomía de Lanús siguió en ámbitos gubernamentales.

El 8 de septiembre de 1919, el Concejo Deliberante de Avellaneda discutió largamente acerca del asunto de la creación de Vieytes, hasta que los diputados conservadores y radicales votaron favorablemente una minuta dirigida a la Cámara de Diputados provincial. La misma solicitaba que se consulte la voluntad de los pueblos antes de proceder al desmembramiento del partido y, en tanto esa medida no se llevara a cabo, manifestaba el rechazo de los concejales a la creación del nuevo distrito. Más tarde, el Concejo Deliberante conformaría un grupo de delegados para que se entrevistaran con los senadores provinciales en nombre del municipio (“Concejo Deliberante", 23 de julio de 1920, p. 3).

Sin embargo, el debate en el Concejo Deliberante de Avellaneda mostró contradicciones semejantes a las de la discusión en el marco del poder legislativo provincial. Oddone, también representante de los socialistas en el ámbito municipal, reprodujo sus argumentos acerca de que las iniciativas antiautonomistas eran promovidas por un grupo minúsculo, que no por reunir un mayor capital debía gozar de una mayor atención de las autoridades, y recordó sus acusaciones en cuanto a los industriales de Valentín Alsina. Mientras tanto, las argumentaciones de los radicales y los conservadores eran semejantes a las esgrimidas por las instituciones que encabezaron el reclamo ante la posible creación del partido de Hipólito Vieytes. ${ }^{22}$ Aunque ambos sectores concordaron completamente -a diferencia de lo ocurrido durante los debates parlamentarios provinciales-, los radicales fueron más activos en cuanto a su participación conjunta con el movimiento antiautonomista de Valentín Alsina. Por ejemplo, el senador provincial Debenedetti hizo público su compromiso de defender una postura contraria a la creación del nuevo partido durante un mitin; la empresa Campomar cedió sus instalaciones para la realización de un festejo convocado por un comité radical; y diversos legisladores municipales y provinciales asistieron a reuniones y manifestaciones públicas que defendían los intereses de Valentín Alsina ("Valentín Alsina”, 7 de octubre de 1919, p. 1; "Unión Cívica Radical”, 9 de noviembre de 1919, p. 1; "Contra el desmembramiento", 3 de agosto de 1920, p. 3 ).

Las justificaciones expuestas para oponerse al proyecto de autonomía de Lanús fueron diversas. Entre las expresiones de la "Comisión pro Avellaneda indivisible", predominaron las referencias a la grandeza de la ciudad y a los efectos nocivos de una posible escisión. Sin ir más lejos, en la asamblea que dio origen a dicha comisión, se aprobó una declaración que sostenía que el organismo pondría por delante la "defensa de la integridad de (...) la tercera ciudad de la república" "Contra la desmembración”, 16 de septiembre de 1919, p. 1). En el mismo sentido se expresaron otras instituciones de distinto tipo, especialmente las vinculadas a los intereses comerciales e industriales del partido, que enfatizaron la importancia de la ciudad y su primer lugar entre las de la provincia por su población ("Contra la desmembración”, 23 de octubre de 1919, p. 1; "Contra la desmembración”, 24 de octubre de 1919, p. 1; "Contra la desmembración”, 25 de octubre de 1919, p. 1; “Contra la desmembración”, 26 de octubre de 1919, p. 3).

Los argumentos vertidos por el “Comité pro-separación de Valentín Alsina de la autonomía de Lanús” y por otras instituciones de la localidad fueron distintos a los anteriores. Se centraron en la cuestión impositiva, los perjuicios que la escisión ocasionaría al notable perfil industrial de la zona y la evaluación positiva acerca de los progresos materiales alcanzados durante la gestión municipal radical encabezada por Manuel Beguiristain. 
En cuanto al tema impositivo, se presentaron cálculos que mostraban que el futuro partido sería deficitario: debería atender las necesidades de una mayor superficie territorial con aproximadamente la tercera parte del presupuesto con el que contaría Avellaneda para responder a las demandas de una superficie semejante. ${ }^{23}$ Además, se afirmaba que esa situación obligaría a aumentar considerablemente los impuestos municipales, siendo Valentín Alsina la que cargaría con el mayor peso por poseer industrias.

De este modo, existió una coincidencia fundamental con los intereses de los industriales de la localidad, los cuales participaron de las instituciones que lideraron el reclamo o prestaron sus firmas para diversas declaraciones. Se creía que las propiedades se desvalorizarían y se verían "seriamente amenazados valiosos capitales e industrias importantísimas que al ser separadas de Avellaneda perderían por este solo hecho gran parte de su importancia" ("Contra el desmembramiento de Avellaneda”, 18 de septiembre de 1919, p. 1). Por último, una mayor contribución económica de Valentín Alsina no era vista como una posibilidad de obtener mayores avances en las condiciones de habitabilidad de la zona sino que, por el contrario, se presentaba como un riesgo de pérdida de lo hasta allí alcanzado. Entre los adelantos mencionados se destacaban el alumbrado eléctrico, las gestiones para proveer el servicio de agua corriente y el adoquinado ("Contra el desmembramiento", 18 de octubre de 1919, p. 3; "Contra el desmembramiento", 19 de octubre de 1919, p. 3; "La creación del partido", 5 de septiembre de 1920, pp. 3 y 5).

Las expresiones más contundentes sostuvieron que una localidad de la importancia de Valentín Alsina a la que se atribuían una decena de industrias que reunían un capital de cincuenta millones de pesos, unos doce mil habitantes y una importante vida comercial- ${ }^{24}$ tenía derecho a obtener su autonomía y no debía subordinarse a un nuevo partido en el que sus problemáticas no serían la prioridad. Asimismo, se recordó un antiguo proyecto que pretendía anexar la localidad a la Capital Federal ("Valentín Alsina", 5 de agosto de 1919, p. 5).

Finalmente, la exposición de los argumentos de carácter legal y político corrió predominantemente por cuenta del propio diario La Libertad. En un editorial se sostuvo que, a pesar de que la Ley Orgánica de Municipalidades de la provincia de Buenos Aires hubiera fijado un número para que los pueblos pudieran obtener un gobierno municipal propio, era preciso tener en cuenta otros elementos: que esas villas cuenten con los recursos necesarios; que los legisladores sancionaran una ley especial; y considerar que las autonomías provinciales favorecían la aparición de los caudillos políticos. ${ }^{25}$ En tanto representante de la Unión Cívica Radical, las expresiones vertidas en el diario fortalecían la idea de que la iniciativa autonomista de Lanús obedecía a intereses políticos coyunturales y minoritarios, acusación similar a la que los socialistas manifestaban acerca de los reclamos de los industriales de Valentín Alsina. 
FIGURA 3

Mitin anti autonomista en Valentín Alsina (octubre de 1919)

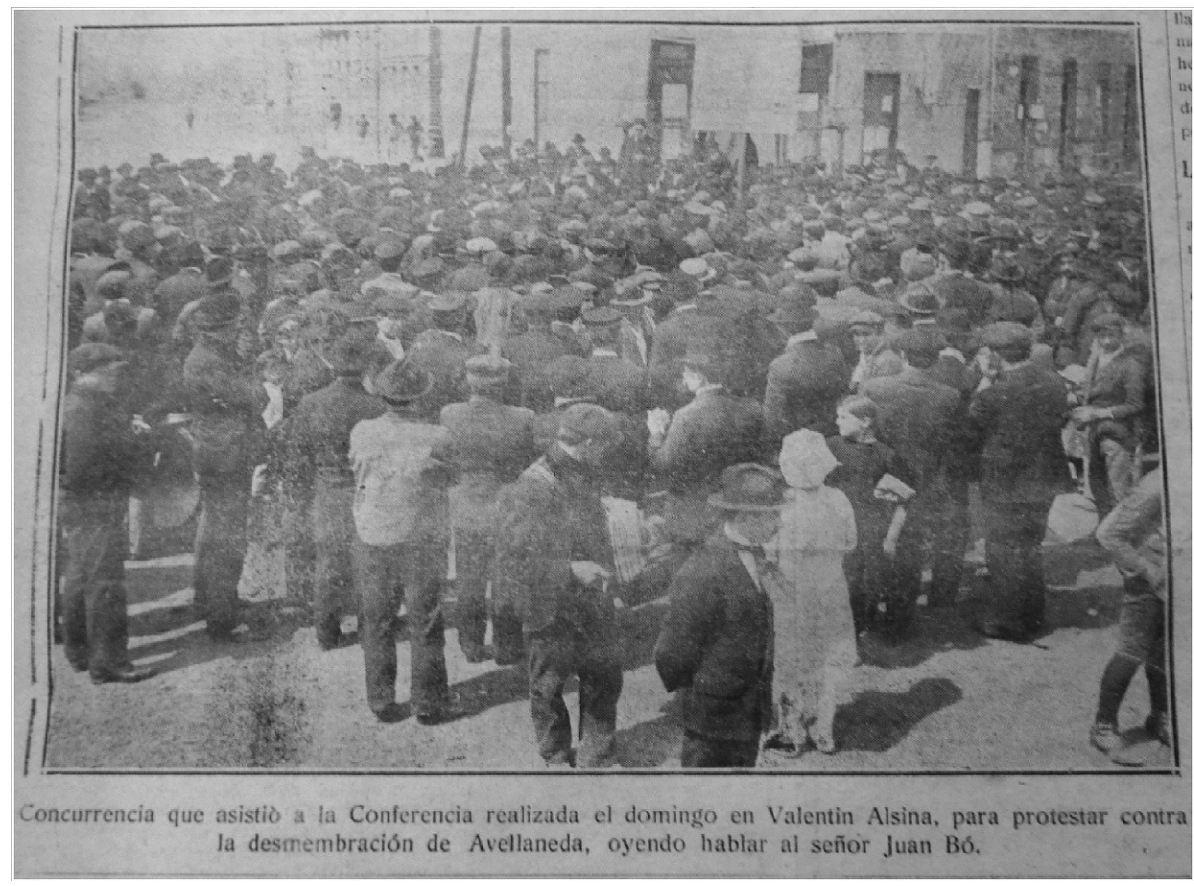

"Valentín Alsina", 7 de octubre de 1919, p. 1.

Por su parte, las actividades que llevaron a cabo las instituciones que se manifestaron en contra de la creación del nuevo partido fueron variadas. En primer lugar, fue necesario que las autoridades de las organizaciones a las que nos referimos se reunieran periódicamente de cara a proyectar las acciones que se emprenderían. Asimismo, se realizaron convocatorias más amplias, como asambleas y mítines. Uno de ellos, convocado en Valentín Alsina, habría llegado a reunir a un total de mil quinientas personas. Mientras tanto, la manifestación a La Plata organizada para asistir a la sesión de la Cámara de Senadores de la Provincia en ocasión de la discusión del proyecto habría contado con unas dos mil quinientas. En este caso se interrumpieron las actividades comerciales e industriales en la localidad y se dispuso de un tren expreso alquilado por el comité antiautonomista ("Valentín Alsina", 7 de octubre de 1919, p. 1; "El pueblo de Alsina", 26 de septiembre de 1920, p. 1; "Valentín Alsina", 5 de octubre de 1920, p. 1; "En el Senado", 5 de octubre de 1920, p. 1).

Pero, probablemente, la iniciativa más habitual fue la elevación de notas y el pedido de audiencias ante las autoridades -como el entonces gobernador de la Provincia de Buenos Aires, José Camilo Crotto, los máximos representantes de las cámaras provinciales de diputados y senadores, o las comisiones pertinentes-. No obstante, también se repartieron miles de volantes, se redactaron memoriales y notas de difusión, se ofrecieron entrevistas ante la prensa del partido y de la Capital Federal, se levantaron firmas, y la Sociedad Italiana Roma de Avellaneda solicitó al senado provincial la realización de una visita de sondeo y estudio de la localidad (“Contra el desmembramiento", 23 de septiembre de 1919, p. 1; "Comisión popular”, 30 de septiembre de 1919, p. 5; "Contra el desmembramiento", 5 de octubre de 1919, p. 1; "Contra el desmembramiento", 14 de octubre de 1919, p. 1; "Contra el desmembramiento", 4 de noviembre de 1919, pp. 3 y 5). Por último, la recepción de donaciones brindó los fondos necesarios para la concreción de estas actividades ("Comisión popular”, 21 de octubre de 1919, p. 1; "Contra el desmembramiento”, 4 de noviembre de 1919, pp. 3 y 5 ).

Un párrafo aparte merece el pedido de un plebiscito que permitiera conocer la opinión de los vecinos a propósito de la iniciativa de creación del nuevo partido. A pesar de que la medida fue aceptada por las autoridades provinciales, y promovida especialmente por los legisladores conservadores, suscitó múltiples críticas y una desacreditación del resultado obtenido. La realización de la consulta había sido solicitada por 
el Centro Comercial e Industrial de Avellaneda a la Cámara de Diputados provincial por medio de un telegrama en septiembre de 1919 y se llevó a cabo finalmente en el mismo mes del año siguiente ("Sobre la creación”, 4 de septiembre de 1919, p. 1; "Contra el desmembramiento", 19 de septiembre de 1919, pp. 1-3). Sin embargo, antes de consumarse, el plebiscito comenzó a cosechar el descrédito de diversas instituciones locales y se organizó una campaña destinada a promover la abstención en la citada consulta. Para ello se utilizaron, por ejemplo, aeroplanos que distribuyeron manifiestos contrarios al plebiscito, donde se sugería no votar. Esta determinación fue compartida también por varios comités radicales ("Contra el desmembramiento", 25 de agosto de 1920, p. 1; "Contra el desmembramiento”, 26 de agosto de 1920, p. 1; "Contra el desmembramiento", 27 de agosto de 1920, p. 1; "Contra el desmembramiento", 1. de septiembre de 1920, p. 1; "Contra el desmembramiento", 4 de septiembre de 1920, p. 3; "Contra el desmembramiento", 7 de septiembre de 1920, p. 1; "Contra el desmembramiento", 19 de septiembre de 1920, pp. 1-3; "Contra el desmembramiento", 21 de septiembre de 1920, p. 1).

Antes de llevarse a cabo, el plebiscito era cuestionado por excluir de la consulta a los habitantes de la sección primera, considerada el núcleo del partido, y por permitir únicamente la participación de las personas inscriptas en los registros electorales, excluyendo a los extranjeros ("Contra el desmembramiento", 25 de agosto de 1920, p. 1). Una vez efectuada la consulta, se cargaron las tintas sobre la escasa representatividad de un acto en el que solo habían participado 101 votantes sobre 561 inscriptos, además de denunciar hechos de fraude ("Contra el desmembramiento", 19 de septiembre 1920, p. 3). Finalmente, estas características del plebiscito fueron determinantes en la decisión del Comité de Partido de la Unión Cívica Radical de solicitar a los senadores provinciales de su bloque la negativa a votar la creación del nuevo partido, inclusive cuando el comité de Lanús había apoyado la iniciativa autonomista ("Contra el desmembramiento", 21 de septiembre de 1920, p. 1).

\section{RefleXiones FinALES}

A lo largo del presente trabajo, el análisis del problema de la pretendida creación del partido de Hipólito Vieytes, a través del estudio del derrotero legislativo que siguió el proyecto y las manifestaciones de oposición que suscitó fundamentalmente en Valentín Alsina, nos ha permitido observar distintas cuestiones y aproximarnos, de manera exploratoria, a distintas problemáticas. A continuación, expondremos algunas de las conclusiones a las que hemos logrado arribar hasta el momento.

En principio, el análisis de los debates parlamentarios nos posibilitó evidenciar la existencia de dos conflictos importantes alrededor del tema de la creación del nuevo distrito. Por un lado, las intervenciones de los legisladores muestran la existencia de acusaciones mutuas al respecto de los intereses electorales de los partidos políticos. Mientras los conservadores atribuían a los socialistas un interés por competir en espacios jurisdiccionales más estrechos, estos últimos sostenían que los conservadores pretendían preservar su poderío en una Avellaneda íntegra, en un contexto de creciente disputa con el radicalismo. A pesar de la diversidad de opiniones expresadas por los legisladores radicales, cabe destacar que los representantes avellanedenses de este sector político emprendieron una vehemente oposición a la división de la ciudad que gobernaban al inicio de las discusiones. Si bien sería preciso profundizar en esta temática, estamos en condiciones de sugerir que estas discusiones podrían haberse relacionado con la importancia adquirida por los ámbitos municipales tras la apertura democrática propiciada por la Ley Sáenz Peña, dado que era allí donde los caudillos y las camarillas locales construían su poderío político y electoral (Bisso, 2007).

Por su parte, la segunda problemática referida fue puesta de manifiesto por los sectores socialistas, quienes propusieron una lectura en términos de clase de los apoyos y las oposiciones al proyecto discutido. De este modo, aseguraron que los obreros eran auténticos defensores de la autonomía, en oposición a los propietarios de Valentín Alsina que manifestaban decididamente su disconformidad con la idea de crear un nuevo partido. Aunque no hemos podido contar con otros elementos para conocer cuál era la posición mayoritaria de los 
sectores obreros de Lanús y Valentín Alsina, el análisis de las acciones llevadas a cabo en esta última localidad confirma la activa participación de renombradas empresas de la zona, como Campomar y Wilson, en el liderazgo del movimiento antiautonomista.

Por otra parte, hemos descripto la variedad de argumentos esgrimidos en contra del proyecto, tanto en Avellaneda como en Valentín Alsina, y procuramos establecer relaciones con las particularidades del desarrollo de ambos espacios. Al respecto, las reflexiones de la "Comisión popular pro Avellaneda indivisible" destacaban el lugar alcanzado por esta ciudad, tercera en importancia de la Argentina y primera de la provincia de Buenos Aires. Por su parte, en Valentín Alsina, las argumentaciones del "Comité pro-separación de Valentín Alsina de la autonomía de Lanús” ponían de manifiesto las especificidades del desarrollo de esta localidad, que, según hemos visto al exponer una breve reseña histórica, se había consolidado de manera autónoma y en forma similar al partido de Avellaneda, en virtud de su privilegiada situación de accesibilidad y la adquisición de un marcado perfil industrial. En este caso, se enfatizó en cuestiones tales como el peso impositivo que recaería sobre la localidad o la presunta desvalorización de las propiedades y los emprendimientos industriales. La progresiva configuración de una identidad local diferenciada y la idea de que la incorporación al nuevo partido de Hipólito Vieytes era una estrategia para que Valentín Alsina afrontara el peso económico de la creación, sin obtener ningún beneficio a cambio, fueron elementos decisivos para la manifestación de un posicionamiento contrario a la autonomía de Lanús. Es dable suponer que, desde la perspectiva de los antiautonomistas de la localidad, más que el mantenimiento de la integridad de Avellaneda, lo que se encontraba en discusión era la relación con la cabecera del futuro partido, respecto de la cual Valentín Alsina parecía encontrarse en una situación de competencia. Los sectores que analizamos no deseaban pertenecer a un nuevo municipio. Por el contrario, algunas de sus manifestaciones más decididas eran favorables a una presunta incorporación a la Capital Federal o bien al logro de una autonomía propia para Valentín Alsina.

Un último elemento a destacar es que, según la diferenciación establecida por Marcela Indiana Fernández, el proyecto de creación de Hipólito Vieytes correspondería al modelo de proceso autonomista derivado de un cambio paulatino, vinculado al surgimiento de demandas locales. En principio, la existencia de reclamos autonomistas desde inicios del siglo XX, así como las continuas referencias al abandono material de Lanús, parecerían demostrarlo. No obstante, es preciso avanzar en el estudio profundo de este y otros casos, a los fines de determinar en qué medida la oposición de algunas de las localidades que serían incorporadas a un nuevo distrito fue una situación frecuente. Asimismo, sería interesante profundizar en las motivaciones de quienes intervinieron en el debate, tanto en representación de los partidos políticos como de la sociedad civil, a través de nuevas fuentes.

\section{Bibliografía}

Álbum Argentino: Libro de estudio de la Provincia de Buenos Aires. (1910) (Vol. II). Buenos Aires.

Álvarez, M. (1993). Historia de Lanús. Telecable Lanús, 8, s./p.

Álvarez, M. (2015). $140^{\circ}$ aniversario de la creación oficial de Valentín Alsina. El Boletín, XXVIII(284), 4-7.

Álvarez, M. (en prensa).Valentín Alsina, de un pueblo proletario a una pujante ciudad.

Barba, F. E. (2009). Un aspecto de la oposición radical yrigoyenista al gobernador Crotto, las interpelaciones parlamentarias. Anuario del Instituto de Historia Argentina 9, 85-96. Recuperado de: http://www.fuentesmem oria.fahce.unlp.edu.ar/art_revistas/pr.3922.pdf.

Bandieri, S. (2001). La posibilidad operativa de la construcción histórica regional o cómo contribuir a una historia nacional más complejizada. En Fernández, S. y Dalla Corte, G. (Comp.), Lugarespara la historia. Espacio, historia regional e historia local en los estudios contemporáneos (pp. 91-117). Rosario: UNR Editora. 
Bandieri, S. (2007). Nuevas investigaciones, otra historia. La Patagonia en perspectiva regional. En Fernández, S. R. (Comp.), Más allá del territorio. La historia regional y local como problema. Discusiones, balances y proyecciones (pp. 47-71). Rosario: Prohistoria.

Bandieri, S. y Fernández, S. (Coord.) (2017a). La historia argentina en perspectiva local y regional (Tomo 1). Buenos Aires: Teseo.

Bandieri, S. y Fernández, S. (Coord.) (2017b). La historia argentina en perspectiva local y regional (Tomo 2). Buenos Aires: Teseo.

Bandieri, S. y Fernández, S. (Coord.) (2018). La historia argentina en perspectiva local y regional (Tomo 3). Buenos Aires: Teseo.

Barbero, M. I. (2009). Estrategias de empresarios italianos en Argentina. El Grupo Devoto. Anuario CEED, 1(1), 10-42. Recuperado de: http://www.economicas.uba.ar/wp-content/uploads/2016/03/CEEED-Estrategias-deempresarios-italianos.pdf.

Barreneche, O. (Dir.) (2014). Historia de la provincia de Buenos Aires (Tomo 5). Buenos Aires / Gonnet: Edhasa / UNIPE: Editorial Universitaria.

Béjar, M. D. (2013). Los conservadores bonaerenses: entre el fraude y las luchas facciosas. En J. M. Palacio (Dir.), Historia de la Provincia de Buenos Aires (Tomo 4) (pp. 309-335). Buenos Aires / Gonnet: Edhasa / UNIPE.

Beliera, J. P. y Beliera, A. A. (1997) El Partido de Escobar. Buenos Aires: edición del autor.

Bisso, M. (2007). Las elecciones municipales platenses de noviembre de 1916. Conservadores, radicales y la 'cuestión local' ante la inminencia de la Intervención Federal. Trabajo presentado en Segundas Jornadas sobre la política en Buenos Aires en el siglo XX. IEHS-UNICEN, Tandil. Recuperado de: http://historiapolitica.com/datos/bibl ioteca/bisso.pdf.

Callegari, H. (1993). Historia del Partido de Tres de Febrero y sus localidades. Caseros: Fundación Banco Cooperativo de Caseros.

Campomar, P. A. R. (1994). Cronología histórica de Monte Grande y su región (el partido de Esteban Echeverría) (Tomo I). Monte Grande: edición del autor.

Canosa, J. A. (2009). Avellaneda. Las obras de infraestructura y las empresas que la hicieron grande. Buenos Aires: edición del autor.

Carbonari, M. R. (2009). De cómo explicar la región sin perderse en el intento. Repasando y repensando la Historia Regional. História Unisinos, 13(1), 19-34. Recuperado de: http://revistas.unisinos.br/index.php/historia/artic le/view/5070.

Ceva, M. (2010). Empresas, trabajo e inmigración en la Argentina. Los casos de la Fábrica Argentina de Alpargatas y la Algodonera Flandria (1887-1955). Buenos Aires: Biblos.

Cutolo, V. O. (1998). Historia de los barrios de Buenos Aires. Buenos Aires: Elche.

De Cristóforis, N. (2016). Inmigrantes y colonos en la provincia de Buenos Aires. Una mirada de largo plazo (siglos XIXXXI). Buenos Aires: Editorial de la Facultad de Filosofía y Letras (UBA).

De Paula, A. S. J., Gutiérrez, R. y Viñuales, G. M. (1974). Del Pago del Riachuelo al Partido de Lanús. 1536-1944. La Plata: Archivo Histórico de la Provincia de Buenos Aires "Ricardo Levene".

Devoto, F. (2003). Historia de la inmigración en la Argentina. Buenos Aires: Sudamericana.

Fernán Cisneros, L., Melián Lafinur, A., Sosa, L. S., Suffern, G., Ortiz, J. L., De Sandoval, R., ... Montero Lacasa, J. (1927). Historia de la ciudad de Avellaneda. La evolución de su progreso económico, edilicio, politico y social. Buenos Aires: Ediciones Argentinas.

Fernández Larrain, F. (1986). Historia del Partido de Avellaneda. Reseña y análisis 1580-1980. Avellaneda: La Ciudad. Fernández Larrain, F. (s.f.). Los dias de Avellaneda.

Fernández, A. (2013). La gran inmigración. En Palacio, J. M. (Dir.), Historia de la Provincia de Buenos Aires (Tomo 4) (pp. 337-362). Buenos Aires / Gonnet: Edhasa / UNIPE: Editorial Universitaria. 
Fernández, M. I. (s.f.). La creación de municipios en la provincia de Buenos Aires: nuevos discursos y viejas prácticas. Espacios (s./n..$\left.^{\circ}\right), 10-19$. Recuperado de: https://periferiaactiva.files.wordpress.com/2014/06/fernandez-m-la-c reacic3b3n-de-municipios-en-la-provincia-de-bs-as-nuevos-discursos-y-viejas-prc3alcticas.pdf.

Fernández, S. (2008). El revés de la trama: contexto y problemas de la historia regional y local. En Bandieri, S., Blanco, G. y Blanco, M. (Coord.), Las escalas de la historia comparada (Tomo 2) (pp. 233-247). Buenos Aires: Miño y Dávila.

Ferrer, A. (2010). La economía argentina. Desde sus origenes hasta principios del siglo XXI. Buenos Aires: Fondo de Cultura Económica.

Folino, N. (1983). Barceló, Ruggierito y el populismo oligárquico. Buenos Aires: Ediciones de la Flor.

Giberti, H. C. E. (1970). Historia económica de la ganadería argentina. Buenos Aires: Solar.

González, C. E. (1944). Lanús Municipio. Argumentos para la autonomía comunal de Lanús. Lanús: s. e.

Greco, J. (1988). Historia de Berazategui. Berazategui: s. e.

Hora, R. (2013). La política bonaerense: del orden oligárquico al imperio del fraude. En J. M. Palacio (Dir.), Historia de la Provincia de Buenos Aires (Tomo 4) (pp. 51-80). Buenos Aires / Gonnet: Edhasa / UNIPE.

INDEC (s.f.). ¿Qué es el Gran Buenos Aires? Recuperado de: www.indec.gov.ar/nuevaweb/cuadros/4/folletogba.pdf. Ippoliti, M. D. (1983). Partido de Lanús: Nuestro hábitat...!. Áncora.

Jensen, S. (2010). Diálogos entre la Historia Local y la Historia Reciente en Argentina: Bahía Blanca durante la última dictadura militar. Trabajo presentado en XIV Encuentro de Latinoamericanistas Españoles (pp. 1426-1447). Universidad de Santiago de Compostela, Centro Interdisciplinario de Estudios Americanistas Gumersindo Busto - Consejo Español de Estudios Iberoamericanos, Santiago de Compostela. Recuperado de: https://halsh s.archives-ouvertes.fr/halshs-00531187/document.

Kessler, G. (Dir.) (2015). Historia de la Provincia de Buenos Aires (Tomo 6). Buenos Aires / Gonnet: Edhasa / UNIPE.

Levene, R. (1941). Historia de la Provincia de Buenos Aires y formación de sus pueblos (Vol. II). La Plata: Publicaciones del Archivo Histórico de la Provincia de Buenos Aires.

Maguid, A. (1997). Migrantes limítrofes en el mercado de trabajo del área metropolitana de Buenos Aires, 1980-1996. Estudios Migratorios Latinoamericanos, 12(35), 31-62.

Medina Rubio, A. (s.f.). Teoría, fuentes y método en Historia Regional (pp. 88-108). Recuperado de: http://www.colm ich.edu.mx/relaciones25/files/revistas/015/AristidesMedinaRubio.pdf.

Míguez, E. J. (2013). Ensayo introductorio. La provincia de Buenos Aires entre 1880 y 1943. En Palacio, J. M. (Dir.), Historia de la Provincia de Buenos Aires (Tomo 4) (pp. 15-47). Buenos Aires / Gonnet: Edhasa / UNIPE: Editorial Universitaria.

Ministerio de Gobierno (1913). Ley Orgánica de las Municipalidades de la Provincia de Buenos Aires. La Plata: Taller de Impresiones Oficiales.

Ministerio de Gobierno (1920). Ley Orgánica de las Municipalidades de la Provincia de Buenos Aires. La Plata: Taller de Impresiones Oficiales.

Municipio de Lanús (2014). Lanús somos todos. $70^{\circ}$ aniversario del Municipio de Lanús (1944-2014). Lanús. Municipio de Lanús.

Ochoa, A. (1938). El Puente Alsina (su Origen, su Historia). Buenos Aires: Comisión Popular de Festejos para la inauguración del Puente Alsina.

Palacio, J. M. (2012). La provincia de Buenos Aires en la historia y en la historiografía. En Otero, H. (Dir.), Historia de la Provincia de Buenos Aires (Tomo 1) (pp. 9-37). Buenos Aires / Gonnet: Edhasa / UNIPE.

Palacio, J. M. (Dir.) (2013). Historia de la Provincia de Buenos Aires (Tomo 4). Buenos Aires / Gonnet: Edhasa / UNIPE: Editorial Universitaria.

Persello, A. V. (2013). El radicalismo bonaerense. En Palacio, J. M. (Dir.), Historia de la Provincia de Buenos Aires (Tomo 4) (pp. 285-308). Buenos Aires / Gonnet: Edhasa / UNIPE: Editorial Universitaria. 
Pesado Palmieri, C. (1987). Las comunicaciones tranviarias en el Sur del Gran Buenos Aires. En Academia Nacional de la Historia, Quinto Congreso Nacional y Regional de Historia Argentina (Tomo II) (pp. 25-42). Buenos Aires: Academia Nacional de la Historia.

Pons, A. y Serna, J. (2007). Más cerca, más denso. La historia local y sus metáforas. En Fernández, S. R. (Comp.), Más allá del territorio. La historia regional y local como problema. Discusiones, balances y proyecciones (pp. 17-30). Rosario: Prohistoria.

Rapoport, M. (2006). Historia económica, politica y social de la Argentina (1880-2003). Buenos Aires: Ariel.

República Argentina (1916). Tercer Censo Nacional. Levantado el $1^{\circ}$ de Junio de 1914 (Tomo 9). Buenos Aires: Talleres Gráfico de L. J. Rosso y Cía.

Rosas, C. (2010). Implicaciones mutuas entre el género y la migración. Mujeres y varones peruanos arribados a Buenos Aires entre 1990 y 2003. Buenos Aires: Eudeba.

Scaltritti, M. (s.f.). Valentín Alsina y sus vecindades: historia barrial (compilación de artículos publicados en el periódico Fuente de Noticias).

Scobie, J. R. (1977). Buenos Aires del centro a los barrios. 1870-1910. Buenos Aires: Solar / Hachette.

Tarcus, H. (Dir.) (2007). Oddone, Jacinto. En Diccionario biográfico de la izquierda argentina (pp. 461-463). Buenos Aires: Emecé.

Terradas I Saborit, I. (2001). La historia de las estructuras y la historia de la vida. Reflexiones sobre las formas de relacionar la historia local y la historia general. En Fernández, S. y Dalla Corte, G. (Comp.), Lugares para la historia. Espacio, historia regional e historia local en los estudios contemporáneos (pp. 179-208). Rosario: UNR Editora.

Torassa, A. A. (1940). El Partido de Avellaneda. 1580-1890. La Plata: Archivo Histórico de la Provincia de Buenos Aires / Taller de Impresiones Oficiales.

Vaccarezza, J. R. y Vaccarezza, O. L. (1972), Historia del Pueblo Vaccarezza y del Partido de Alberti. La Plata: Archivo Histórico de la Provincia "Dr. Ricardo Levene".

\section{Fuentes}

Autonomía municipal. (27 de julio de 1919). La Libertad, p. 1.

Comisión popular pro Avellaneda indivisible. (30 de septiembre de 1919). La Libertad, p. 5.

Comisión popular pro Avellaneda indivisible. (21 de octubre de 1919). La Libertad, p. 1.

Concejo Deliberante. Autonomía de Lanús (23 de julio de 1920). La Libertad, p. 3.

Contra el desmembramiento de Avellaneda. (3 de agosto de 1919). La Libertad, p. 3.

Contra el desmembramiento de Avellaneda. (18 de septiembre de 1919). La Libertad, p. 1.

Contra el desmembramiento de Avellaneda. (19 de septiembre de 1919). La Libertad, pp. 1-3.

Contra el desmembramiento de Avellaneda. (23 de septiembre de 1919). La Libertad, p. 1.

Contra el desmembramiento de Avellaneda. (5 de octubre de 1919). La Libertad, p. 1.

Contra el desmembramiento de Avellaneda. (14 de octubre de 1919). La Libertad, p. 1.

Contra el desmembramiento de Avellaneda. (18 de octubre de 1919). La Libertad, p. 3.

Contra el desmembramiento de Avellaneda. (19 de octubre 1919). La Libertad, p. 3.

Contra el desmembramiento de Avellaneda. (4 de noviembre de 1919). La Libertad, pp. 3 y 5.

Contra el desmembramiento de Avellaneda. (5 de noviembre de 1919). La Libertad, p. 3.

Contra el desmembramiento de Avellaneda. (25 de agosto de 1920). La Libertad, p. 1.

Contra el desmembramiento de Avellaneda. (26 de agosto de 1920). La Libertad, p. 1.

Contra el desmembramiento de Avellaneda. (27 de agosto de 1920). La Libertad, p. 1.

Contra el desmembramiento de Avellaneda. (1. e septiembre de 1920). La Libertad, p. 1. 
Contra el desmembramiento de Avellaneda. (4 de septiembre de 1920). La Libertad, p. 3.

Contra el desmembramiento de Avellaneda. (7 de septiembre de 1920). La Libertad, p. 1.

Contra el desmembramiento de Avellaneda. (19 de septiembre de 1920). La Libertad, pp. 1-3.

Contra el desmembramiento de Avellaneda. (21 de septiembre de 1920). La Libertad, p. 1

Contra la creación del partido 'Hipólito Vieytes'. (14 de septiembre de 1919). La Libertad, p. 1.

Contra la desmembración de Avellaneda. (16 de septiembre de 1919). La Libertad, p. 1.

Contra la desmembración de Avellaneda. (23 de octubre de 1919). La Libertad, p. 1.

Contra la desmembración de Avellaneda. (24 de octubre de 1919). La Libertad, p. 1.

Contra la desmembración de Avellaneda. (25 de octubre de 1919). La Libertad, p. 1.

Contra la desmembración de Avellaneda. (26 de octubre de 1919). La Libertad, p. 3.

DSCD (Diario de Sesiones de la Cámara de Diputados de la Provincia de Buenos Aires) (6 de agosto de 1919). 66. periodo, Tomo II, 22. a sesión ordinaria (p. 1188). La Plata: Taller de Impresiones Oficiales.

DSCD (20 de agosto de 1919). 66. ${ }^{\circ}$ periodo, Tomo II, 24.a sesión ordinaria (p. 1242). La Plata: Taller de Impresiones Oficiales.

DSCD (27 de agosto de 1919). $66^{\circ}$ periodo, Tomo II, 25.a sesión ordinaria (pp. 1384-1407). La Plata: Taller de Impresiones Oficiales.

DSCD (24 de septiembre de 1919). $66^{\circ}{ }^{\circ}$ periodo, Tomo II, 4.a sesión de prórroga (pp. 1583-1609). La Plata: Taller de Impresiones Oficiales.

DSCD (1. ${ }^{\circ}$ de octubre de 1919). 66. ${ }^{\circ}$ periodo, Tomo II, 5.a sesión de prórroga (pp. 1638-1662). La Plata: Taller de Impresiones Oficiales.

DSCS (Diario de Sesiones de la Cámara de Senadores de la Provincia de Buenos Aires) ( 7 de octubre de 1919). 66. ${ }^{\circ}$ periodo, 6. a sesión de prórroga (p. 532). La Plata: Taller de Impresiones Oficiales.

DSCS (5 de octubre de 1920). 66. periodo, 4.a sesión de prórroga (pp. 388-413). La Plata, Taller de Impresiones Oficiales.

DSCS (19 de octubre de 1920). 66. periodo, 5.a sesión de prórroga (pp. 437-440, 442-445). La Plata: Taller de Impresiones Oficiales.

DSCS (26 de octubre de 1920). 66. periodo, 6.a sesión de prórroga (pp. 452-477). La Plata: Taller de Impresiones Oficiales.

El pueblo de Alsina demostrará esta tarde que no quiere separarse de Avellaneda. (26 de septiembre de 1920). La Libertad, p. 1.

En el Senado. (5 de octubre de 1920). La Libertad, p. 1.

Honorable Concejo Deliberante. Parte del acta de la sesión que realizó el Departamento Deliberativo el 8 de Septiembre de 1919. (30 de septiembre de 1919). La Libertad, p. 5.

Honorable Concejo Deliberante. Parte del acta de la sesión que realizó el Departamento Deliberativo el 8 de Septiembre de 1919. (1. e octubre de 1919). La Libertad, p. 5.

Honorable Concejo Deliberante. Parte del acta de la sesión que realizó el Departamento Deliberativo el 8 de Septiembre de 1919. (2 de octubre de 1919). La Libertad, p. 5.

Honorable Concejo Deliberante. Parte del acta de la sesión que realizó el Departamento Deliberativo el 8 de Septiembre de 1919. (3 de octubre de 1919). La Libertad, p. 5.

Honorable Concejo Deliberante. Parte del acta de la sesión que realizó el Departamento Deliberativo el 8 de Septiembre de 1919. (4 de octubre de 1919). La Libertad, p. 5.

Honorable Concejo Deliberante. Parte del acta de la sesión que realizó el Departamento Deliberativo el 8 de Septiembre de 1919. (5 de octubre de 1919). La Libertad, p. 5.

La autonomía de Lanús. Una nota del pueblo de Valentín Alsina. (25 de febrero de 1919). La Libertad, p. 1.

La creación del partido de 'Hipólito Vieytes. (5 de septiembre de 1920). La Libertad, pp. 3 y 5. 
La Nación (10 de noviembre de 1875), p. 2.

La Nación (11 de noviembre de 1875), p. 2.

La Prensa (22 de octubre de 1875), p. 2.

La Prensa (29 de octubre de 1875), p. 2.

La Prensa (30 de octubre de 1875), p. 2.

La Prensa (31 de octubre de 1875), p. 2.

La Prensa (5 de noviembre de 1875), p. 2.

La Prensa (28 de noviembre de 1875), p. 2.

La Prensa (2 de diciembre de 1875), p. 2.

La Prensa (16 de diciembre de 1875), p. 2.

La Prensa (24 de diciembre de 1875), p. 2.

La Prensa (28 de diciembre de 1875), p. 2.

Sobre la creación del nuevo partido de 'Hipólito Vieytes. (4 de septiembre de 1919). La Libertad, p. 1.

Un año de vida diaria. (5 de agosto de 1919). La Libertad, p. 3.

Unión Cívica Radical en Valentín Alsina. (9 de noviembre de 1919). La Libertad, p. 1.

Valentín Alsina demostrará hoy su voluntad de seguir formando parte de Avellaneda. (5 de octubre de 1920). La Libertad, p. 1.

Valentín Alsina en contra de la autonomía. (5 de agosto de 1919). La Libertad, p. 5.

Valentín Alsina y la creación del partido de 'José Hipólito Vieytes. (7 de octubre de 1919). La Libertad, p. 1.

\section{Notas}

1. Se han citado aquí los tomos correspondientes al periodo de interés del presente artículo y del proyecto más general en el que se inscribe. Otros tomos completos o capítulos incluidos en ellos son citados a lo largo del trabajo.

2. Hemos tenido la oportunidad de comprobar la existencia de este interés más acentuado a través del relevamiento de bibliografía correspondiente al área de los estudios migratorios durante los últimos 25 años aproximadamente. A modo de ejemplo, citaremos la aproximación clásica de Alicia Maguid (1997) y un trabajo más reciente, el de Carolina Rosas (2010).

3. Debido a la importante cantidad de estudios relevados, evitaremos citarlos aquí en forma completa. Muchos de esos análisis han sido valiosos para la elaboración del apartado de esta introducción, correspondiente a la descripción de la evolución histórica de Valentín Alsina, razón por la cual serán citados oportunamente en dichas páginas.

4. Además de los trabajos citados, cabe destacar una obra en tres tomos, de reciente publicación, que reúne contribuciones historiográficas basadas en una perspectiva local y regional (Bandieri y S. Fernández, 2017a; Bandieri y S. Fernández, 2017b; Bandieri y S. Fernández, 2018).

5. Cabe aclarar que este trabajo se inscribe en un proyecto de mayor alcance, destinado a la elaboración de una tesis doctoral en Historia. Su objetivo es contribuir a la comprensión de las profundas transformaciones socioeconómicas que afectaron al área metropolitana de la provincia de Buenos Aires en la primera mitad del siglo XX y, especialmente, a la ampliación del conocimiento acerca del influjo de la inmigración transatlántica en un espacio particular de la provincia de Buenos Aires (Valentín Alsina), en una etapa durante la cual este proceso estuvo estrechamente relacionado con otros dos: la constitución del denominado Gran Buenos Aires y el devenir de un desarrollo industrial que capitalizó las migraciones trasatlánticas de diversas maneras.

6. A los fines de referirnos a la evolución histórica del área de nuestro interés, utilizaremos el término localidad con el sentido que se le da a la palabra en el uso corriente, en tanto lugar o pueblo, definido sobre la base de la tradición y el conocimiento de los vecinos. Esta condición es habitualmente refrendada por las legislaturas de los partidos (INDEC, s.f., p. 5).

7. Esta situación se ha visto modificada recientemente, tras la inauguración (en el mes de septiembre de 2018) del Puente Lacarra, que une el partido de Lanús con el barrio porteño de Villa Soldati.

8. Daniel Solier fue un militar y político de origen francés. Participó activamente de la Guerra de Paraguay, donde fue malherido en la batalla de Curupaytí. Por esa razón, la nomenclatura de las calles de Valentín Alsina recuerda mayoritariamente eventos de dicha contienda (Álvarez, 2015, p. 4). 
9. Cabe señalar que diversos autores señalan fechas diferentes para la fundación del frigorífico. Tal es el caso de Fernández Larrain (1986) y Barbero (2009), quienes indican 1901 y 1903 respectivamente. Por gentileza de la historiadora local Mabel Álvarez hemos podido constatar el año 1905 como el de inicio de la faena (durante el mes de junio), mientras que en mayo de 1902 había sido constituida la sociedad anónima y en junio de 1903 se adquirió el terreno. A partir de aquel momento, se llevaron a cabo las obras correspondientes. Esta información proviene de una recopilación de artículos periodísticos del periódico El Pueblo, de próxima publicación (Álvarez, en prensa).

10. En este punto es preciso aclarar que existen posiciones encontradas acerca de la empresa que adquirió el Frigorífico Argentino. Horacio Giberti (1970, p. 198) señala que el frigorífico fue adquirido en 1914 por la empresa Sulzbeerger and Sons, mientras que algunos historiadores locales afirman que la compañía que pasó a gestionar el establecimiento industrial fue Wilson and Co. (Canosa, 2009, pp. 186-187).

11. La denominación del partido pretendía rendir homenaje, a pesar del error en el nombre, al comerciante, periodista, político y militar Juan Hipólito Vieytes, quien participara activamente de la Revolución de Mayo de 1810. Con el transcurrir de los debates, la denominación sería reemplazada por la de Hipólito Vieytes, eliminando el primer nombre.

12. Para una perspectiva general acerca de la política bonaerense en el periodo ver: Roy Hora (2013).

13. Como es sabido, Alberto Barceló fue una figura de vital importancia para la vida política de Avellaneda, donde supo cosechar importantes triunfos electorales y derrotar a los radicales sin recurrir al fraude. Su ascenso político como intendente (cargo que ejercieron en reiteradas oportunidades tanto él como miembros de su familia), lo convirtió en presidente del comité conservador de la tercera sección electoral, en 1915, y en el primer conservador bonaerense en acceder al parlamento nacional en 1916. En 1923 lideró la conformación del Partido Provincial (Béjar, 2013, pp. 312-316; Hora, 2013, p. 70).

14. Si bien excede las pretensiones del presente trabajo, es preciso señalar aquí que por aquellos días el radicalismo atravesaba una división interna. La presentación del proyecto para la creación del partido de Vieytes se produjo durante la gobernación de José Camilo Crotto, quien asumiera sus funciones el 1. ${ }^{\circ}$ de mayo de 1918. Crotto era un representante de la tendencia metropolitana (vinculada más fuertemente con el radicalismo nacional y la Capital Federal) y fue elegido para la candidatura por su cercanía con el presidente Hipólito Yrigoyen. No obstante, tras tomar su cargo, el gobernador llevó a cabo el nombramiento de sus ministros sin consultar a la máxima autoridad nacional, ocasionando una ruptura entre los sectores afines a Crotto y los sectores yrigoyenistas. Esta conflictividad habría de conducir a la renuncia de Crotto en el mes de mayo de 1921 (Barba, 2009, pp. 85-96; Persello, 2013, pp. 269-299).

15. Jacinto Oddone (1881-1968) fue un destacado miembro del Partido Socialista que, además de legislador y futuro intendente de Avellaneda, se desempeñó como dirigente gremial e historiador del movimiento obrero. De origen italiano, arribó a la Argentina con apenas tres años. Más tarde se formaría en el oficio de tornero y se afiliaría al Partido Socialista. En 1918 fue elegido primer concejal socialista de Avellaneda (Tarcus, 2007, pp. 461-463).

16. Cuando mencionaba a la gestión municipal vigente, el diputado Oddone se refería al intendente radical Manuel Beguiristain, cuyo mandato se extendió entre el 2 de mayo de 1918 y el 2 de enero de 1920.

17. Un ejemplo del segundo tipo de autonomía es el del proyecto “Génesis 2000”, que dio origen a los partidos de José C. Paz, Malvinas Argentinas, San Miguel, Hurlingham, Ituzaingó, Ezeiza y Presidente Perón en 1994.

18. Alberto de Paula, Ramón Gutiérrez y Graciela Viñuales (1974, pp. 158-161) ubican los más remotos antecedentes de los reclamos autonomistas de Lanús en el apoyo que los vecinos de la zona brindaron a la creación del partido de Lomas de Zamora en 1861. No obstante, la conformación de un movimiento autonomista organizado debió esperar hasta las dos primeras décadas del siglo XX. Algunos vecinos notables de la zona tomaron la iniciativa de su conformación en 1906 y algunos años después, en 1911, se constituyó el “Comité Popular Pro Lanús”.

19. El proyecto aprobado incluyó la modificación de los límites previstos para el partido, lo cual implicó una pequeña reducción de su extensión. El partido de Hipólito Vieytes estaría "formado por las tierras que hoy constituyen la segunda sección de policía de Avellaneda, o sea las comprendidas entre el camino a la Plata (concesión Otto Franke), la calle Chile hasta los terrenos del frigorífico Wilson, de ésta desviando por calle Florida hasta Entre Ríos y por ésta al Riachuelo; los partidos de Quilmes y Lomas de Zamora” (DSCS, 7 de octubre de 1919, p. 532).

20. Esta publicación apareció por primera vez el día 9 de mayo de 1915 y adoptó una frecuencia diaria a partir del 4 de agosto de 1918 (República Argentina, 1916, p. 322; "Un año de vida diaria”, 5 de agosto de 1919, p. 3). A lo largo de 1919 y 1920, La Libertad constaba habitualmente de unas ocho páginas y no disponemos de información acerca de su tiraje. Se presentaba a sí mismo como órgano oficial de la Unión Cívica Radical, razón por la cual fue frecuente la difusión de las actividades oficiales del Intendente Manuel Beguiristain. No obstante, la publicación de información oficial continuó aun durante la gestión del socialista Jacinto Oddone. A ella se sumó la profusa inclusión de noticias de los distintos barrios que componían el partido, como veremos detalladamente para el caso de Valentín Alsina. El diario La Libertad se encuentra disponible para su consulta tanto en la Biblioteca Zeballos (Avellaneda, Provincia de Buenos Aires, Argentina) como en la Biblioteca Nacional (Buenos Aires, Argentina).

21. Asistieron organizaciones de muy diverso tipo: el propio Centro Industrial y Comercial de Avellaneda y varias instituciones asociadas a él, distintos clubes deportivos como Independiente y Racing Club, instituciones de carácter 
étnico como el Centro Gallego de Avellaneda, y numerosas sociedades de fomento e instituciones educativas. Asimismo, por la Unión Cívica Radical, se hicieron presentes el comité de Valentín Alsina y el subcomité de Villa Diamante. También participaron la Asociación Empresarios de Construcción, el Círculo de Obreros, la Sociedad Cosmopolita de Valentín Alsina, la Logia Ferrer Guardia y el ya mencionado Comité pro separación de Valentín Alsina.

22. El acta de la sesión del Concejo Deliberante de Avellaneda correspondiente al 8 de septiembre de 1919 fue reproducida por La Libertad en un apartado de publicación sucesiva, cuyas apariciones citamos a continuación: "Honorable Concejo Deliberante", 30 de septiembre de 1919, p. 5; "Honorable Concejo Deliberante”, p. 5; "Honorable Concejo Deliberante", 2 de octubre de 1919, p. 5; "Honorable Concejo Deliberante", 3 de octubre de 1919, p. 5; "Honorable Concejo Deliberante", 4 de octubre de 1919, p. 5; "Honorable Concejo Deliberante", 5 de octubre de 1919, p. 5.

23. Se calculaba que el nuevo partido sumaría 58 kilómetros a partir de la integración de los cuarteles $5 .^{\circ}, 8 .^{\circ} \mathrm{y}$ partes del $3 .^{\circ} \mathrm{y}$ $4 .^{\circ}$. A Avellaneda le quedarían 54 kilómetros. Del total del presupuesto de Avellaneda para 1918 se calculó que solamente $\$ 338.070$ correspondían a la zona que integraría el nuevo partido y \$1.048.488 a Avellaneda. "Valentín Alsina", 5 de agosto de 1919, p. 5.

24. Desconocemos la nómina de estas empresas, aunque las referencias sobre Campomar, el Frigorífico Wilson y la importancia del rubro textil en la zona brindan un panorama del perfil industrial de la localidad.

25. “Autonomía municipal”, 27 de julio de 1919, p. 1. En este punto, debemos aclarar que hemos tenido acceso a la Ley Orgánica de Municipalidades de 1913. En ella solo se establece una cantidad de habitantes para diferenciar a aquellos casos en los que, por no superar los dos mil vecinos, el gobierno municipal estaría a cargo de una Comisión de Vecinos y no de un Intendente y un Consejo Deliberante, tal cual se preveía para el resto. Estas cuestiones permanecen inalteradas en la Ley Orgánica de Municipalidades de 1920 (Ministerio de Gobierno, 1913, p. 3; Ministerio de Gobierno, 1920, p. 44). 